\title{
Pneumomastia: A Rare Cause of Breast Swelling
}

\author{
Mike Kipling Christopher Christou Ludger Barthelmes \\ Department of Breast and General Surgery, Cumberland Infirmary, Carlisle, Cumbria, UK
}

\author{
Keywords \\ Pneumomastia - Emphysema - Breast · Bronchopleural \\ fistula - Thoracotomy
}

\section{Summary}

Background: Pneumomastia is air within the breast parenchyma. A number of causes have been reported for this condition. This case report describes a new cause and details of the management strategy applied, together with a review of the literature. Case Report: We describe a case of acute breast swelling in a 40-year-old woman and its subsequent successful conservative management. Conclusion: Bronchopleural fistula after thoracotomy is a risk, and can cause pneumomastia. This is more likely to occur after redo thoracic surgery. Pneumomastia after repeat thoracotomy can be managed conservatively, even in the presence of a bronchopleural fistula.

\section{Introduction}

Breast swelling or asymmetry is a fairly typical presentation in many breast clinics. However, it rarely presents acutely, and there are a number of important causes. The following report describes one such case, detailing the case and its subsequent successful conservative management, as well as exploring the literature regarding the clinical problem.

\section{Case Report}

A 40-year-old female presented to Accident and Emergency on 23 January 2012 with $24 \mathrm{~h}$ of dramatic, painless right breast swelling. A nonsmoker, she had been in good health until rheumatic fever had caused

\author{
Schlüsselwörter \\ Pneumomastie - Emphysem - Brust - Bronchopleurale \\ Fistel - Thorakotomie
}

\section{Zusammenfassung}

Hintergrund: Pneumomastie ist Luft im Brustparenchym. Mehrere Ursachen für diese Erkrankung sind bekannt. Mit dem vorliegenden Fallbericht beschreiben wir eine neue Ursache und Details der Behandlung. Des Weiteren wird eine Übersicht über die Literatur gegeben. Case Report: Wir beschreiben einen Fall von akuter Schwellung der Brust bei einer 40-jährigen Frau und die anschließende erfolgreiche konservative Behandlung. Schlussfolgerung: Bronchopleurale Fisteln sind ein Risiko der Thorakotomie und können Pneumomastie verursachen. Das Eintreten eines solchen Zustandes ist wahrscheinlicher bei Wiederholung von Thorax-Operationen. Pneumomastie nach wiederholter Thorakotomie kann selbst bei Vorliegen einer bronchopleuralen Fistel konservativ unter Kontrolle gebracht werden.

mitral valve destruction in her mid-30s, necessitating a mitral valve repair. This failed some years later, with recurrent regurgitation causing cardiac failure. On 9 January 2012 she underwent a revision of her mitral valve surgery, with a repeat median sternotomy and insertion of a metallic mitral valve at a tertiary centre outside of the region. Postoperative medications included amiodarone and, notably, warfarin. The presentation to Accident and Emergency was 14 days postoperatively, without shortness of breath or bruising. After initial examination by the emergency physician, she was referred for 'further management of likely breast haematoma'. However, when examined by the surgical registrar, surgical emphysema was readily palpable, respiratory examination was normal in a well-looking patient, and the international normalized ratio (INR) was in-range. A chest X-ray and computed tomography scan were performed. After consulting with the cardio-thoracic unit that had implanted the heart valve, the patient was transferred there for observation, but was discharged after a total period of 1 week as the swelling gradually began to resolve with oxygen therapy.

\section{KARGER \\ Fax +497614520714 \\ Information@Karger.com}

www.karger.com (c) 2013 S. Karger GmbH, Freiburg

1661-3791/13/0083-0218\$38.00/0

Accessible online at:

www.karger.com/brc
Michael David Kipling, MRCS

The Barn, East Batter Law Farm

Hawthorn, Seaham, County Durham

SR7 8RP, UK

mikekipling@doctors.org.uk 


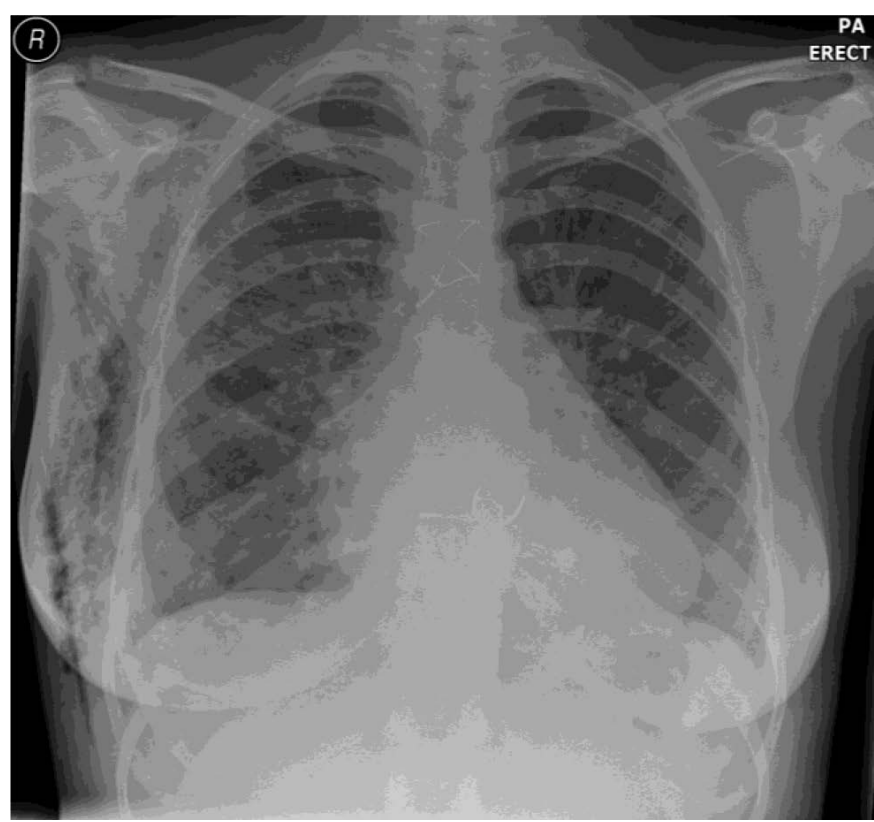

Fig. 1. X-ray of pneumomastia.

\section{Discussion}

The cases of pneumomastia that have been previously described [1-5] have mostly been due to a transient, iatrogenic cause such as direct instrumentation of the breast during surgery, mechanical ventilation, thoracic surgery, or spread of emphysema from laparoscopic insufflation, in the absence of an underlying continuous driving pathology (necrotising in- fection [6], oesophageal perforation, and pneumothorax can also cause pneumomastia, but usually cause abnormalities on examination). In this case there was a bronchopleural fistula which would have provided a continuous source of air to fill the breast. However, despite the presence of this fistula 'feeding' the crepitus, conservative management of pneumomastia was still successful. To the authors knowledge this is the first reported case of pneumomastia caused by a bronchopleural fistula.

In conclusion, clinicians need to be mindful of this pathology, and careful clinical examination by a surgeon is recommended should such a case be encountered. Had the emergency physician attempted either needle centesis or drainage in the emergency department in this case, creation of an open pneumothorax or bronchocutaneous fistula would have been possible, with conservative management more likely to fail subsequently. Exclusion of pneumothorax and oesophageal perforation prior to commencing conservative therapy is the key to safe conservative management, which can succeed even in the presence of a bronchopleural fistula. This and other reports have shown pneumomastia to be more likely following redo thoracic surgery [3], so care should be taken upon entering the thorax for a second time.

\section{Disclosure Statement}

The authors declare that they have no competing interests, their work being unfunded and not sponsored.

\section{References}

1 Green DH: An unusual case of pneumomastia: mammographic appearances. BMJ Case Reports 2011; doi:10.1136/bcr.03.2010.2852.

2 Franco T, Franco D, Treiger N: (Subcutaneous emphysema during breast augmentation: case report) (Portuguese). Rev Bras Anestesiol 2007:57:414-20.
- 3 Pülzl P, Greiner A, Schoeller T, Wechselberger G: Breast enlargement after thoracoscopic sympathectomy. J Plast Reconstr Aesthet Surg 2008;61:711-2.

4 Vargas FC, Vas W, Carlin B, Morris L, Salimi Z: Radiographic and CT demonstration of mammary emphysema. J Comput Assist Tomogr 1985;9:560-2.
5 Mannarino E, Lupattelli G, Schillaci G: A 32-yearold woman with breast swelling and crepitant rales. CMAJ 2004;171:1172.

6 Delotte J, Karimdjee BS, Cua E, et al.: Gas gangrene of the breast: management of a potential life-threatening infection. Arch Gynecol Obstet 2009;279:79-81. 